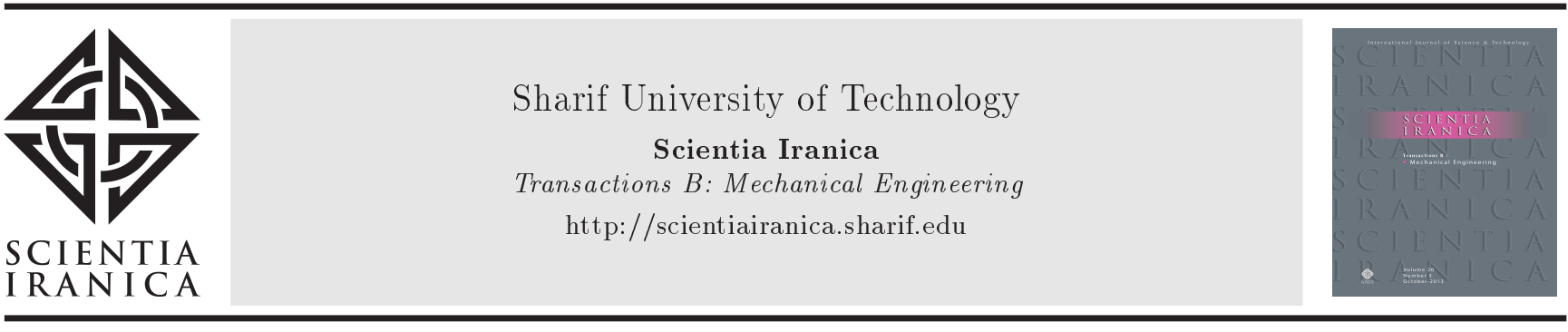

\title{
Microstructure and fatigue fracture mechanism for a heavy-duty truck diesel engine crankshaft
}

\author{
K. Aliakbari ${ }^{\mathrm{a} *}$, M. Imanparast ${ }^{\mathrm{b}}$, and R. Masoudi Nejad ${ }^{\mathrm{c}}$ \\ a. Department of Mechanical Engineering, Faculty of Montazeri, Khorasan Razavi Branch, Technical and Vocational University \\ (TVU), Mashhad, Iran. \\ b. Department of Mechanical Engineering, University of Sistan and Baluchestan, Zahedan, Iran. \\ c. Department of Mechanical Engineering, Foolad Institute of Technology, Fooladshahr, Isfahan, 84916-63763, Iran.
}

Received 4 May 2018; received in revised form 7 June 2018; accepted 23 July 2018

\section{KEYWORDS}

Fatigue crack growth;

Fractography;

Crankshaft;

Finite element;

Fracture mechanics.

\begin{abstract}
The main goal of this research is the experimental and numerical study of the fatigue function and failure of the crankshaft of the diesel engine of a heavy truck. To this end, a crankshaft of the diesel engine of a heavy truck that underwent failure after traveling $955000 \mathrm{~km}$ was used. The crack developed from the third crankpin, leading to final failure in the fillet of the 4 th crankpin. To investigate the roots of this failure, several experimental studies were carried out. Besides, by using a three-dimensional finite element method, the location of the maximum stress in the crankshaft was determined using "complete crankshaft model" and "one-crank model". The application of the results of stress analysis was the basis for the crack growth model and fatigue life estimation to determine the stress intensity factor and fatigue life considering the related parameters and boundary conditions. At the final stage, by using the results obtained from the given model for the fatigue crack growth, comparing them with experimental results, and examining the whole process, it was concluded that the scratches in crankpin region were the main reason for the fatigue failure obtained from the bending-torsional load-combination.
\end{abstract}

(C) 2019 Sharif University of Technology. All rights reserved.

\section{Introduction}

In recent decades, following the emergence of numerical and non-destructive tests and powerful analytical software models, a great body of research has been carried out on the fatigue crack growth as the main failure source of mechanical parts [1-3]. Failure of the crankshaft in the internal combustion engines results from various factors such as insufficient oil between bearings of the main journal and the crankpin, the emergence of a crack between the crankpin-web fillets, the misalignment of the crankshaft, the failure of

\footnotetext{
*. Corresponding author.

E-mail address: karim.aliakbari@gmail.com (K. Aliakbari).
}

doi: $10.24200 /$ sci. 2018.50964 .1939 fatigue obtained from torsional and bending loads, and the impulses of combustion. The initiation of crack and its propagation are most often found in the regions where the stresses are at their maximum level, unless there is an external factor such as impurities in the material or the scratch of the crankshaft. Therefore, it can be concluded that determining the location of stresses in these regions is useful for examining the nondestructive tests and the methods of life estimation [4$5]$.

Fonte et al. [6] studied the effect of steady torsion on fatigue crack growth under rotating bending. The comparative results of the same stress ratio and relevant differences in fatigue crack growth are investigated based on crack closure concepts. Fonte et al. [7] presented fatigue crack growth on rotating bending axles and shafts with or without an applied steady 
torsion. The results showed that crack growth rates decreased with increasing mode III for cyclic mode I $\left(\Delta K_{\mathrm{I}}\right)+$ static mode III $\left(K_{\text {III }}\right)$ loading. Fonte et al. [8] compared short crack growth rates with long crack growth rates on cylindrical test specimens under rotary or alternating bending combined with steady torsion on power rotor shafts. Results showed a significant reduction in the crack growth rates when a steady torsion mode III was superimposed on cyclic mode I. Martins et al. [9] performed mode-III and mode-I fatigue loading tests on standard Compact Tension (CT) specimens. Fracture surfaces obtained under mode I loading using optical devices revealed that crack grew flat, coplanar, and normal to the tensile axis, as expected. Moreover, Stress Intensity Factors (SIFs) present at the tip of each branch crack loaded under mode III were calculated through Finite Element Method (FEM). Ghahremani Moghadam et al. [10] carried out extensive research on the growth of fatigue crack due to the residual stresses in mechanical parts. Masoudi Nejad et al. [11-14] examined the growth of fatigue crack and life estimation of bandage wheel of the railway obtained from contact stresses and heating residual stresses. The results showed that the crack growth in the Iran railway wheel was due to the shear combined modes II and III without residual stress. Masoudi Nejad et al. [15] carried out another research to investigate the stress field obtained from the production procedure of the railway wheel. To this end, a three-dimensional elastic-plastic finite element model was constructed to estimate the given stress field. The comparison between the results obtained from this study and laboratory experimental results shows expected standards. The existence of the notches or the stresses concentrated in the crankshaft is unavoidable due to the variation of crankshaft diameter. To decrease the stress concentration, the fillets have been used. The crack initiation in the crankshaft has been identified, and the main origin of the crack is commonly close to the crankpin-web fillet or the main journal fillets. Another source of the crack is the use of improper fillets with an improper radius or an improper improvement in crankpin connection and fillets of the main journal. Since a crankshaft is an important part in a vehicle, many studies have carried out the numerical analysis and the main source of crankshaft failure [16-18]. Moore et al. [19] studied and analyzed the source of continuous failure of two cast steel crankshafts and drew the following conclusion: The woody fracture was initiated from the second crankpin perpendicular to the direction of piston load. Location, orientation, and size of the woody fracture were alike. The fracture region in the direction of applied stresses caused secondary cracks. The woody fracture existed before final machining and heating operation. The segregated regions contained $\mathrm{MnS}$ impurities, higher carbon, and tampered martensite bands all over the crankshaft. The crack growth from the fillets of the woody fracture plan in the hardened region continued with low-cycle fatigue. The propagation of fatigue crack was affected by the combination of torsional and bending loads. Farrahi et al. [20] examined the fracture analysis of some crankshafts of a four-cylinder diesel engine. The results of Scanning Electron Microscopy (SEM) revealed the cleavage fracture, proving that it was of brittle fracture type. The results of FEM showed that the most vulnerable point was related to the fillet of the last crankpin (the closest to the flywheel). The experimental and numerical results suggested re-examining the crankshaft design. Fonte et al. [21] evaluated and analyzed the failure of two crankshafts of an agricultural diesel engine. Each of the two crankshafts underwent different crack initiation, and the fatigue was the main source of the failure of both crankshafts. Crankpin of both crankshafts was under the reversed bending load, and the mode I was the cause of failure. Crack growth in each crankshaft appeared in the region of the crankpin-web fillet, and the form of symmetrical half-elliptical cracks indicated mode I. The results of FEM also showed that the fillets of crankpin-web were the most vulnerable parts. They suggested making a crankshaft based on the experimental and numerical results and re-examining the design and quality control.

Other related parameters involved in fatigue crack growth, such as initial crack angle and loading type, were studied in [22-25]. Concerning fatigue crack growth affected by residual stresses in bandage wheels, Masoudi Nejad et al. [26-29] investigated the fatigue crack growth and life estimation of railway bandage wheel affected by contact stresses and heating residual stresses. The results of these research pieces showed the growth of a crack in the wheel of Iran's railway system due to the combined shear modes II and III without residual stress. Fonte et al. [30] studied the failure analysis of two crankshafts of a diesel engine. The first crankshaft broke down in the third crankpin following 1100 hours of functioning, and the second crank broke down after 105000 hours of functioning in the first crankpin. Crack initiation is seen to bear a relation to the crankpin-web fillets. The form of cracks was a half-elliptical symmetrical type and failure was mode I. Alfares et al. [31] examined the bus that had traveled $300000 \mathrm{~km}$ and analyzed the breakdown of a six-cylinder diesel engine of this public bus. Crack initiation in the crankshaft is related to the fillets of both crankpin and the main journal. They concluded that the removal of the partial nitride layer of both crankpin and main journal decreased the fatigue strength, leading to crack initiation and propagation. The crack source and the form of symmetrical half-elliptical cracks indicated mode I. 
Silva [32] studied the two damaged crankshafts of the diesel engine. Therefore, he carried out grinding operation on the crankshafts having traveled 300000 $\mathrm{km}$. The results showed that wrong grinding operation caused damage, leading to small thermal fatigue crack initiation. Becerra et al. [33] analyzed the failure of the two crankshafts of a diesel engine. The first crankshaft experienced failure after having traveled 1100 hours in the third crankpin, and the second crankshaft experienced failure after having traveled $105000 \mathrm{~km}$ in the first crankpin. Crack growth in both crankshafts is associated with the crankpin-web fillets. The form of the cracks was symmetrically half-elliptical under opening mode I. Aliakbari et al. [34] examined the failure of the crankshafts of the wheel loader diesel engine. The crankshaft experienced failure after having traveled 4800 hours in the fifth crankpin. Crack growth in the crankshaft is related to the crankpin-web fillet root. The morphology of fracture surface showed that the fracture was of smooth type and occurred due to the fatigue. Aliakbari [35] carried out another research on examining the light-duty truck diesel engine crankshaft failure. The failure occurred by fatigue crack growth, which was initiated from a surface defect after about $95000 \mathrm{~km}$ in the second crankpin from the crankpinweb fillet, where the stress concentration was at the highest level.

Most of the work on crack growth is related to crack initiation prediction. Some are also related to crack propagation. However, the issue of crack growth, while considering stress field, has never received enough attention. This study considers the required parameters and simulates the maximum stress in the crankshaft, leading to the failure of the crankshaft of a diesel engine of a heavy truck. Then, the results were studied and used as a basis for fatigue crack growth using boundary conditions. In order to determine the cause of failure, several experimental studies including determining chemical composition, the strength of the material, and microstructure of crankshaft were carried out.

\section{Material and methods}

The chemical composition of the crankshaft of the diesel engine of a heavy truck was carried out using ASTM E415-14 and ASTME1086 standards by a spectrophotometer machine of SPECTROMAXx model made in Germany. Its geometrical dimension was determined using micrometer and Verner Caliper made by Mitutoyo company of Japan. Then, some microscopic observations were done using a Samsung camera featuring $8 \mathrm{MP} \mathrm{AF}$ and the size of $1.22 \mu \mathrm{m}$. To examine hardness value, the microstructure of crankshaft crosssection of the second crankpin with a thickness rate of $15 \mathrm{~mm}$ of crankpin of the crankshaft was cut off

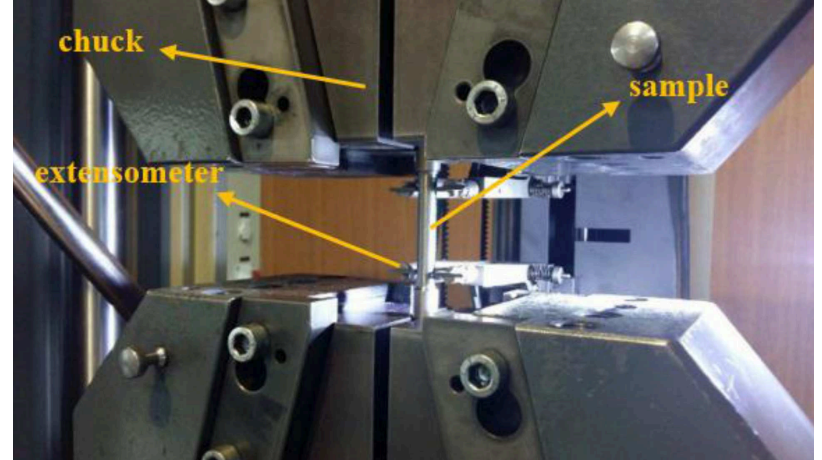

Figure 1. Servohydraulic Zwick machine, tension test sample, and an extensometer.

by a wire cut EDM machine; then, it was sandpapered using rough and soft sheets on the sample. For the final polishing, diamond paste was used, and the washing was completed by alcohol and dried using hot air.

To examine the mechanical properties of the crankshaft such as ultimate stress, yield stress, and elongation, the samples were cut off by a wire cut EDM machine and, then, were exposed to machinery using CNC turning. The samples were used in compliance with ASTM E8M-97a standard, and the method for doing the experiment was the basis of $[36,37]$. The simple tension test was done by Zwick model 4100/425 servohydraulic machine with a capacity of 25 tons. Figure 1 shows the test machine, tension test sample, and extensometer. The results of the test with a sampling rate of 2 times in a second in the form of forcedisplacement were stored. The displacement changes of the samples were done by an extensometer with a length measurement of $50 \mathrm{~mm}$. To perform the test, the displacement rate of the grips was $0.05 \mathrm{~mm}$ per minute. Figure 2 shows the standard samples of tension test before and after the experiment.

To observe the microstructure, immersion etching using Nital $2 \%$ and microscope images by an optical microscope from different parts of the cross-section of the crankpin was carried out. The hardness test was performed based on the ASTM: E384-11e1 standard by a hardness measurement device that applied $30 \mathrm{~kg}$ force $(294.18 \mathrm{~N})$ in 10 seconds. To examine the broken surface, first, the broken sample of the crankshaft was cut off by a wire cut EDM machine, and the sample was put in ultrasonic bath for an hour. Then, the images were prepared using SEM, LEO model 1450VP made by Germany.

\section{Experimental results and discussion}

The sample case studied in this research is to examine the crankshaft failure of a six-cylinder heavy-duty truck diesel engine, whose characteristics are shown in Table 1. Figure 3 shows the failure location of the middle point of the 4th crankpin to the 3 rd crankpin 


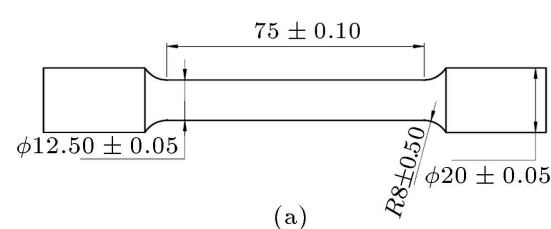

(a)

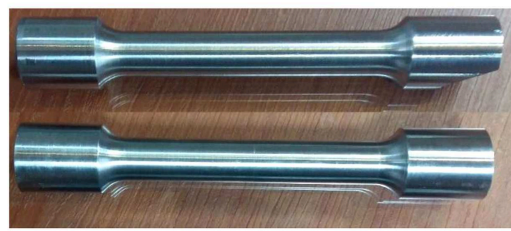

(b)

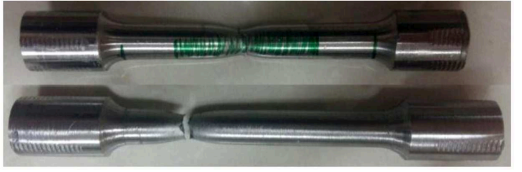

(c)

Figure 2. Sample dimension of tension test: (a) Configuration of a $12.5 \mathrm{~mm}$ diameter test sample, (b) the standard samples before the test is done, and (c) the standard samples after the test is done.

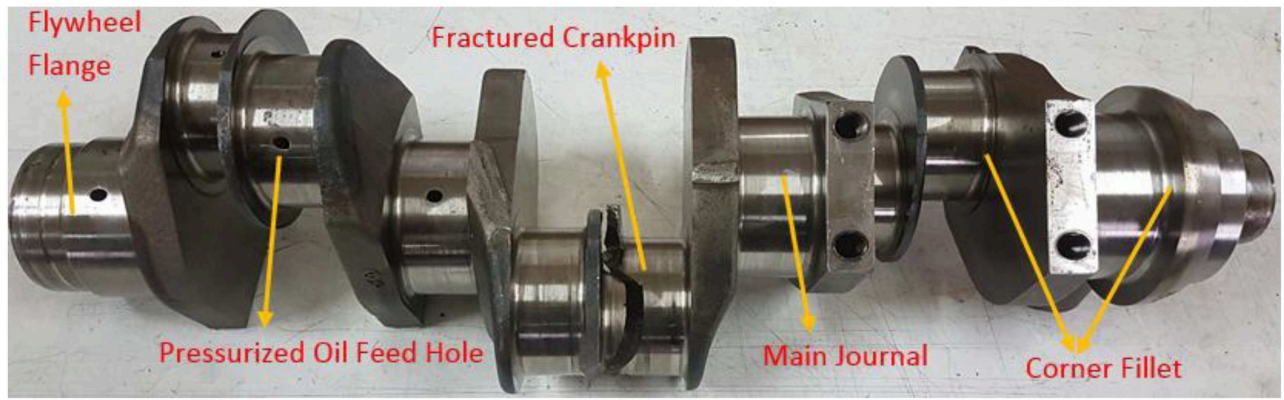

Figure 3. Photograph of the broken-down crankshaft at the 4th crankpin.

Table 1. Engine specifications and conditions.

\begin{tabular}{lc}
\hline Max. power $(\mathrm{kw} / \mathbf{r p m})$ & $290 / 1800$ \\
Max. torque (Nm/rpm) & $1850 / 1080$ \\
Bore (mm) & 100 \\
Stroke (mm) & 105 \\
Cylinder pressure (bar) & 78.5 \\
\hline
\end{tabular}

Table 2. Crankshaft specifications and conditions.

\begin{tabular}{lc}
\hline \multicolumn{1}{c}{ Crankshaft parameter } & Specification (unit) \\
\hline Crankshaft mass & $54.43 \mathrm{~kg}$ \\
Crankshaft length & $590 \mathrm{~mm}$ \\
Main journal diameters & $108 \mathrm{~mm}$ \\
Crankpin diameters & $94 \mathrm{~mm}$ \\
Operation & $955000 \mathrm{~km}$
\end{tabular}

fillet after having traveled $955000 \mathrm{~km}$. Its measurement specifications are listed in Table 2.

\subsection{Chemical analysis}

Table 3 shows the chemical composition of the elements of the material of the broken crankshaft compared with the applied standard specifications based on the weight percentage. The quantity of the determining elements shown in Table 3 is equivalent to steel 38MnVS6/DIN1.1303 of Germany DIN standard.

\subsection{Tensile behavior}

Table 4 shows the mechanical properties of the materials of the crankshaft compared with the applied standard specification, and Figure 4 shows the diagram of engineering stress-strain of them. The quanti-
Table 3. The chemical composition of DIN1.1303 and standard alloy.

\begin{tabular}{ccc}
\hline Symbol & DIN1.1303 & Standard alloy \\
\hline $\mathrm{Fe}$ & 97.2 & Base \\
$\mathrm{C}$ & 0.353 & $0.34-0.41$ \\
$\mathrm{Si}$ & 0.59 & $0.15-0.8$ \\
$\mathrm{Mn}$ & 1.36 & $1.2-1.6$ \\
$\mathrm{P}$ & 0.013 & $\leq 0.025$ \\
$\mathrm{~S}$ & 0.02 & $0.02-0.06$ \\
$\mathrm{Cr}$ & 0.174 & $\leq 0.3$ \\
$\mathrm{Mo}$ & 0.005 & $\leq 0.08$ \\
$\mathrm{~V}$ & 0.096 & $0.08-0.2$ \\
\hline
\end{tabular}

ties obtained from the tensile tests are within the framework of applied standard specification equal to DIN1.1303/38Mn VS6 steel.

\subsection{Hardness}

As Figure 5 shows, the hardness depth is $5 \mathrm{~mm}$. In order to increase fatigue life, compression stresses are used on the surface of the part. Nitriding and carburizing are the suggested methods. Nitriding of the surface is preferred to carburizing due to its low temperature and its acceptable dimension tolerance for the final surface [38].

As shown in Figure 6, as expected from the results of hardness test, the surface of the part underwent surface hardness, and it has a tinier microstructure than the central part. Similar investigations of hardness (e.g., [3,17]) reported the existence and the increasing trend of the surface towards the center in the crankpin journal by case-hardening treatment. Due to the 
Table 4. Mechanical properties of current work (DIN1.1303) and standard alloy.

\begin{tabular}{ccccc}
\hline Symbol & $\boldsymbol{\sigma}_{\boldsymbol{Y}}(\mathbf{M P a})$ & $\boldsymbol{\sigma}_{U}(\mathbf{M P a})$ & Elongation $(\%)$ & Young's modulus $(\mathrm{GPa})$ \\
\hline Standard alloy & Min. 520 & $800-950$ & Min. 12 & - \\
Current work & 626.5 & 927.1 & 13.8 & 210 \\
\hline
\end{tabular}

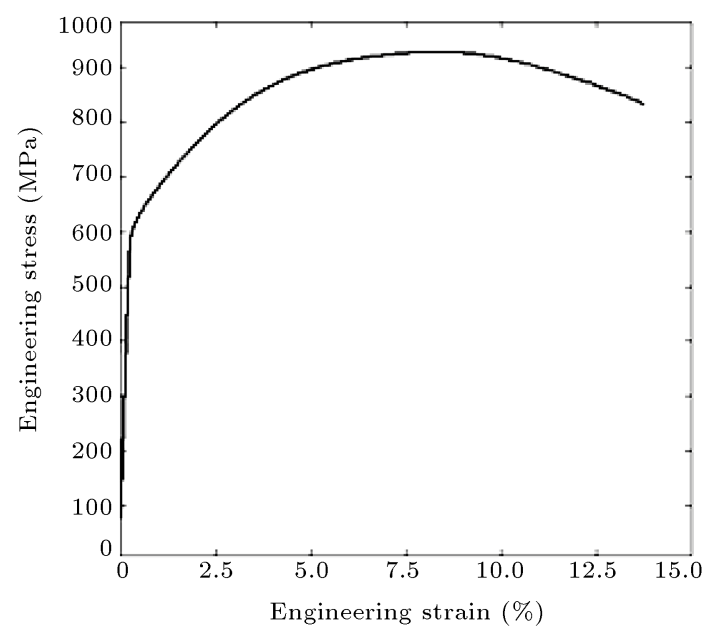

Figure 4. Engineer stress-strain curve of crankshaft material.

observation of the microstructure of crankshaft in Figure 6, the matrix is formed by ferrite-pearlite as pointed in [30].

\subsection{Fracture surface}

Locating the source of fracture is the first goal of fractography science, which facilitates the proper analysis of the cause of fracture. The signs of formed fracture can be likened to the map of a road for evaluating the fracture. The initiation and propagation of crack create specific signs of the fractured surface such as river signs, radial lines, chevrons, and beach signs, thus showing crack direction. These signs are used to guess the source of crack. The appearance of such signs on the fracture surface is a factor that follows the type of tension, shear, bending, fatigue, or torsion loading. It also follows stress mode, the magnitude of stress, the existence of stress concentrators, and environmental and material factors. One of the macroscopic features of observing fatigue fracture is related to the emergence of the signs of a ratchet, especially in the shafts. These signs emerge in places where several fatigue crack origins grow and, then, they are linked to each other. The signs of the ratchet are step-like junctions between adjacent fatigue cracks [39]. Figure 7 shows the fracture location of sample crankshaft, the scratch location, crack initiation, and crack propagation. The scratch can be produced due to factors such as overloading, probable misalignment of the crankshaft on journal bearings, severe wear, the incorporation of impurities to lubrication, and an increase in the lubrication temperature.

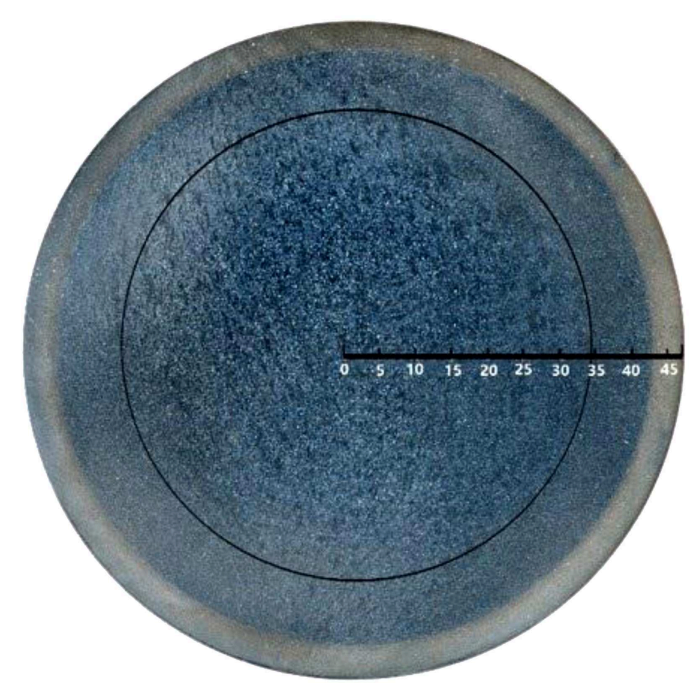

(a)

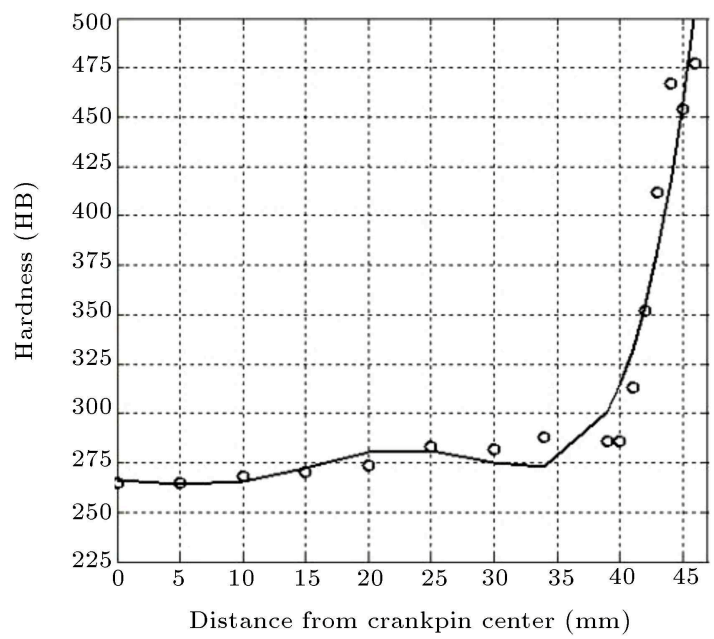

(b)

Figure 5. Hardness distribution from center to outer diameter of the crankpin.

Figure 8 shows samples of the fracture surface of the crankpin, the crack initiation location, the crack propagation, and also the final fractured location. The fracture surface morphology shows a smooth crack initiation with the beach marks and ratchet marks and the second crack propagation zone with beach marks and final fast fracture zone near the end. According to the orientation of beach marks, it can be concluded that fracture starts from the middle part of the crankpin of the crankshaft by arrow. To locate the source of fracture in Figure 8, SEM images with different magnified sizes were prepared. The image of the 


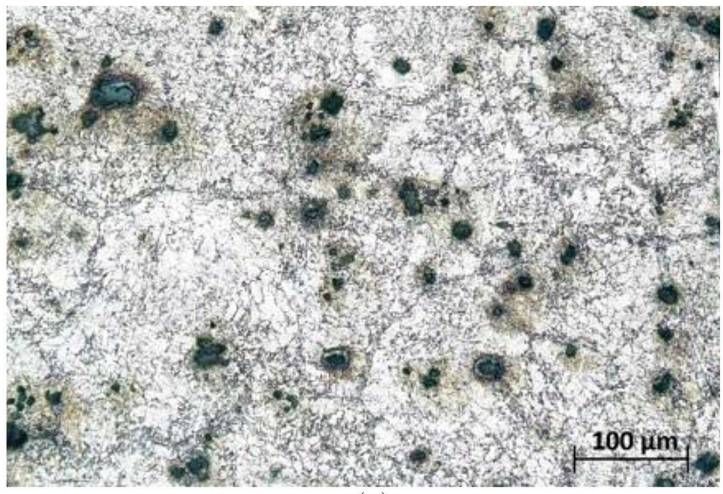

(a)

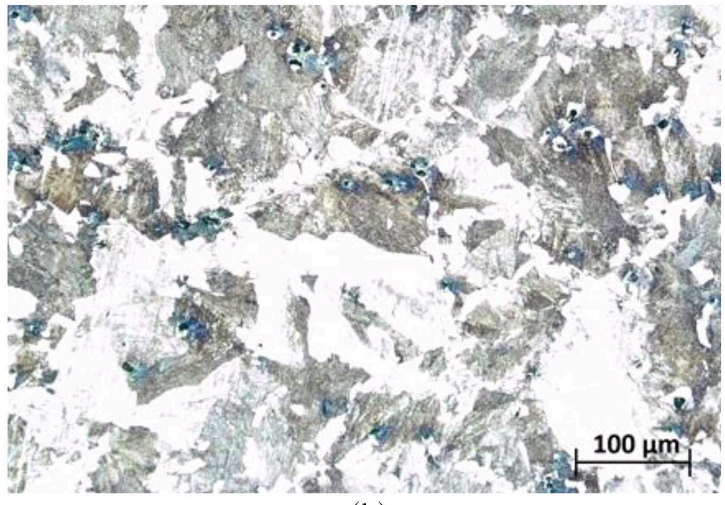

(b)

Figure 6. The two images of the material of the crankshaft with a magnification of 100: (a) The outer surface, and (b) the inner surface.

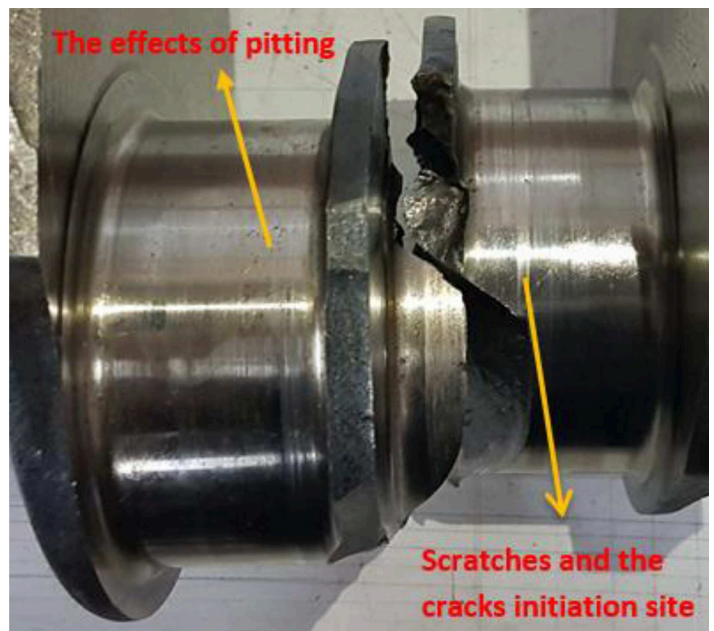

Figure 7. The fracture surface of the 4 th crankpin.

fracture surface captured by SEM shows the direction of intergranular crack growth (see Figure 9). Besides, it should be mentioned that the impurities observed in the images were negligible.

\section{Evaluation of fatigue crack growth}

\subsection{Stress analysis}

Stress analysis of the crankshaft for the purpose of

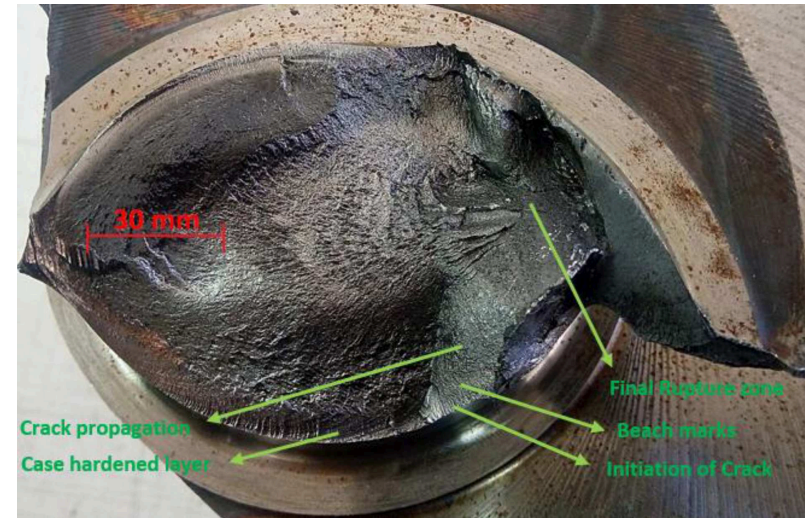

Figure 8. The fracture zones on the crankpin surface.

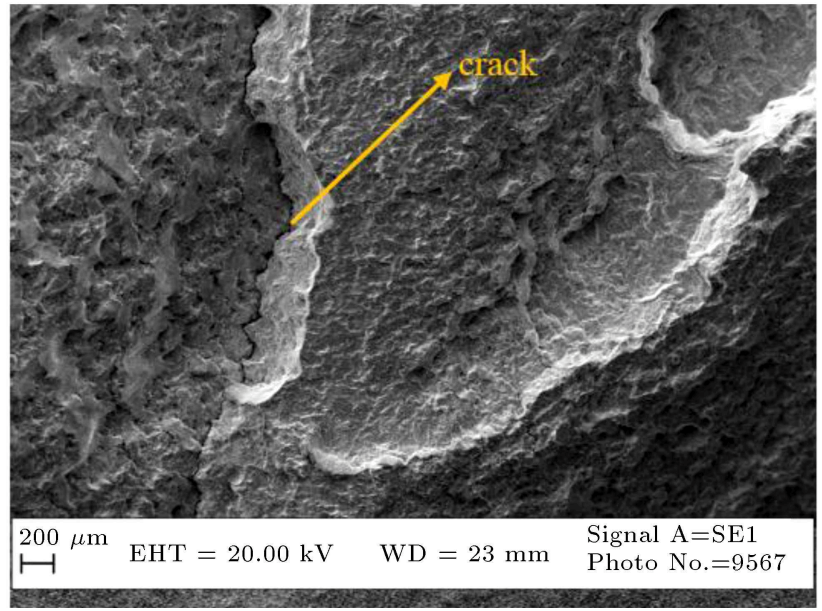

Figure 9. SEM image, crack propagation, and inter-grain fracture.

determining the level of stress concentration in fracture region is done by Finite Element Method (FEM). The analysis of the stress of a complete crankshaft and a camshaft model was studied in [40-42]. The stress analysis of the one-crank model was studied in [4344]. Both models are studied in this research. Due to the crankcase, oil temperature in diesel engines is seen in the range of $90-110^{\circ} \mathrm{C}$; thus, according to [4546 , in this temperature range, about $10 \%$ of the yield and tensile strength is reduced. On the other hand, according to Farrahi et al. [20] and Fonte et al. [41], the maximum stresses of the torsional and bending forces are about $15 \%$ and $30 \%$ of yield strength occurring in the crankpin fillet regions. It appears that the achievement of mechanical properties of engineering stressstrain diagram at ambient temperature is similar to true stress-strain diagram considering the temperature ranges and the maximum stresses. First, the geometry of the crankshaft was simplified and, then, meshing, element modeling, application of boundary constraints, the way of applying load, and stress analysis were done. In this research, bending $\left(F_{x}\right)$, torsional $\left(F_{y}\right)$, and longitudinal $\left(F_{z}\right)$ force directions are mentioned in 
the crankshaft coordinate geometry. The simplification of the crankshaft is done as follows:

1. Disregard for oil ways in the direction of the main journal and crankpin bearings;

2. The drilled holes in the counterweight to balance the crankshaft;

3. Disregard for the crank web slope and the thickness of the crank web in the current model, considered at the same level.

The presence of these cases complicates the geometry of the crankshaft. It does not have any effect on the stress at critical locations [41]. The quadratic tetrahedral and triangular elements were used for meshing the geometry of the crankshaft according to Figure 10. These elements are usually used for meshing complicated geometries [47]. Therefore, due to the complexity of the geometry of the crankshaft, the results of linear elements are of lower accuracy. The application of quadratic elements increases the accuracy and decreases the rigidity of the geometry. Mostly triangular elements are used in the areas with high stress gradients and mostly large tetrahedral elements are used in the zones that are farther away and are not within the applied forced zone. Altogether, 482920 elements were used for a complete crankshaft model, and 263387 elements were used for the one-

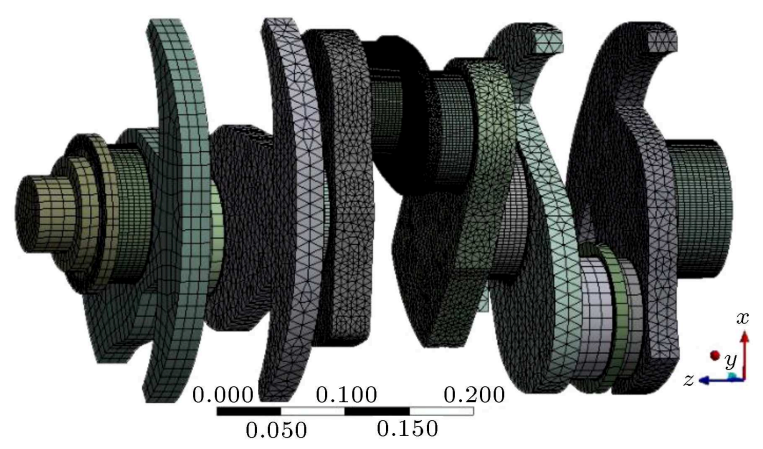

(a)

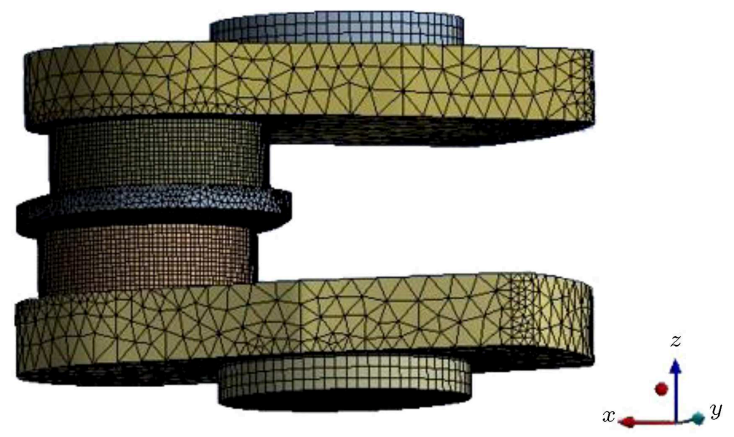

(b)

Figure 10. Finite element modeling of crankshaft: (a) The complete crankshaft model, and (b) the one-crank model. crank model. The number of the complete crankshaft elements was 1.83 times that of the one-crank model, prolonging the problem-solving time.

According to Ref. [44], the front side of the crankshaft has been fixed in all degrees of freedom directions; however, the end side of the crankshaft has been fixed in two directions. The distribution of the load on the connecting rod bearing on the uniform pressure of 120 degrees in the contact area was done. The load distribution was done by Webster et al. (1983) based on an experimental test [48]. By considering the combustion pressure and cylinder diameter in Table 1, the applied force on the bearing is $104 \mathrm{KN}$ in the $F_{x}$ direction. While the crankshaft is rotating, the crankshaft on the crank is affected by different forces. To analyze the conditions of different loadings and determine dangerous locations, three analysis cases of the stress of pure bending loads, pure torsional, and bending-torsional loads in different angles were implemented. After examining the case, only the pure bending loads perpendicular to the crankpin have the maximum applied stress, and the other loads are negligible. Figure 11 shows the stress distribution of von Mises of the complete crankshaft model and the one-crank model during the combustion. Both have the same quantity, and the difference is negligible. The stress distribution of von Mises of both crankpins is shown in Figure 12 during the combustion. In Figures 11 and 12, the stress distribution of von Mises in the crankpin fracture zones is 344.4 and $261.06 \mathrm{MPa}$, respectively. This is equal to $55 \%$ and $22 \%$ of the yield stress of crankshaft material. High stress occurs in the crankpin-web fillet. However, crack initiation is in the middle part of the crankpin, as shown in Figure 4.

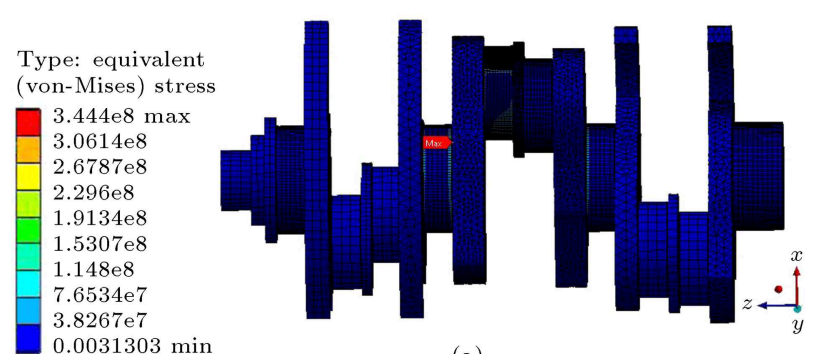

(a)
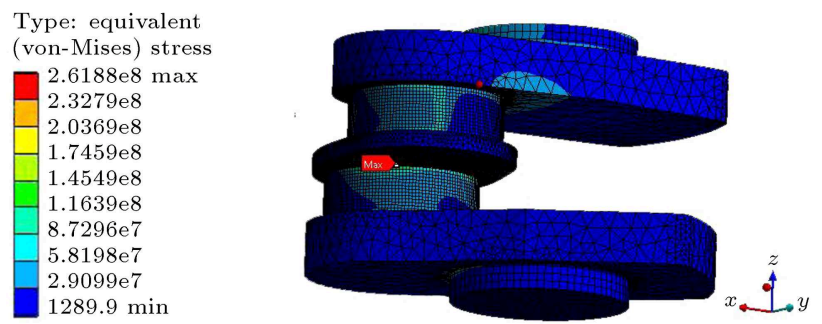

(b)

Figure 11. Von Mises stress distribution in (a) the complete crankshaft model and (b) the one-crank model. 


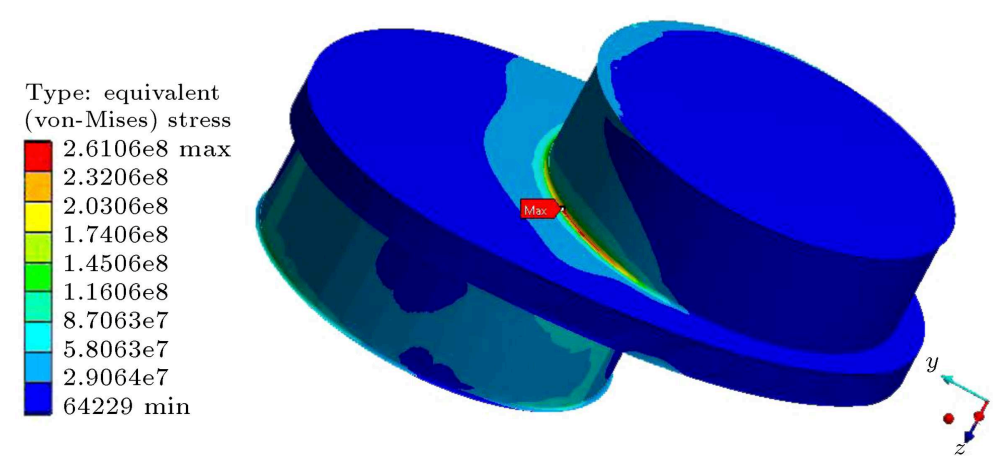

Figure 12. Stress distribution of Von Mises in both crankpins.

Considering the results of FEM and images of the fracture surface, scratches occurring in the middle part of the crankpin represent the only factor responsible for fatigue failure of bending-torsional type, leading to the crack growth initiation.

\subsection{Fatigue crack growth}

To simulate fatigue crack growth, a number of researchers at Cornell University used the boundary elements method by Frank 3D software [49,50]. The modeling and mechanical properties of the crankshaft are the same as those in the previous section. In Figure 13, the boundary element model and its crack are shown.

This study shows the geometry of crack in the quarter-elliptical form in the plan, obtained from stress analysis. The reason for selecting this form of crack is the comprehensiveness of the crack and the samples that are observed in the fracture of the crankshaft. The initial crack length examined for different cracks is determined with a dimension of $0.5,1.5$, and $2 \mathrm{~mm}$. Being loaded, the sample meshes. Then, the stress analysis is carried out by Boundary Element Solver (BES) software. The values of the stress intensity factor are calculated for mode I. Accordingly, the values of stress intensity factor to measure crack growth are determined. There are two possible crack growth forms in 3-Frank software crack growth: manual and automated forms. In manual crack growth, the value of crack growth is optional. It should be mentioned that crack growth should not exceed $30 \%$ of the all previous cracks. The direction of crack growth is calculated based on the maximum tangential stress criterion. After determining the direction of crack growth, it is possible to fix tip curve of the crack and let the crack grow to another stage. After the growth, the sample is meshed. Now, it is ready to be solved. This process should be repeated for each crack growth. Crack growth can be repeated up to 14 stages in order to reach the critical length of $38 \mathrm{~mm}$. As the process continues, after obtaining appropriate information and calculating the value of stress intensity factor, the fatigue life of the crankshaft is calculated. The crack growth rate and fatigue life can be obtained through the equations in [51-53]. In this research, the improved equation of Paris has been used, and the effect of fatigue crack closure has also been taken into account. The growth rate based on this equation is defined as follows [54]:

$$
\frac{d a}{d N}=C\left(\Delta K_{e f f}\right)^{n}=C\left(K_{\max }-K_{o p}\right)^{n}
$$

where $\Delta K_{\text {eff }}$ is the effective stress intensity factor and is equal to the difference between the maximum mode I stress intensity factor $\left(K_{\max }\right)$ and the stress level needed for opening the crack tip, $K_{o p}$. The factors $C$
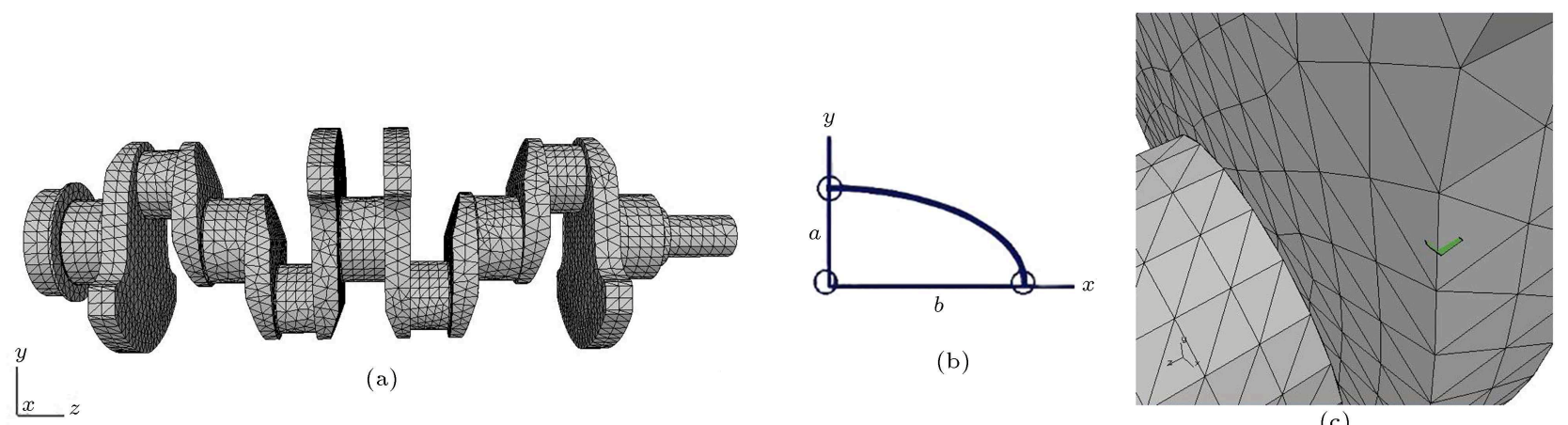

(c)

Figure 13. Boundary element model in Franc 3D software: (a) Geometric modeling of crankshaft, (b) geometry of initial crack, and (c) crack position and configuration in the crankshaft. 
and $n$ in these equations are the material constants. In this study, they are $C=3.89 \times 10^{-9} \mathrm{~m} /$ cycle and $n=3.12$. The function of crack opening, $f$, for plasticity-induced closure of the crack by Newman is defined as follows [55].

$$
\begin{aligned}
f= & \frac{K_{o p}}{K_{\max }} \\
& =\left\{\begin{array}{cc}
\max \left(R_{\text {ratio }}, A_{0}+A_{1} R_{\text {ratio }}+A_{2} R_{\text {ratio }}^{2}\right. \\
+A_{3} R_{\text {ratio }}^{3} & R_{\text {ratio }} \geq 0 \\
A_{0}+A_{1} R_{\text {ratio }} & -2 \leq R_{\text {ratio }} \prec 0
\end{array}\right.
\end{aligned}
$$

The coefficients of the above equations are obtained by the following equations:

$$
\begin{aligned}
& A_{0}=\left(0.825-0.34 \alpha+0.05 \alpha^{2}\right)\left[\cos \left(\frac{\pi}{2} S_{\max } / \sigma_{0}\right)\right]_{(3)}^{\frac{1}{\alpha}} \\
& A_{1}=(0.415-0.071 \alpha)^{S_{\max } / \sigma_{0}} \\
& A_{2}=1-A_{0}-A_{1}-A_{3}, \\
& A_{3}=2 A_{0}+A_{1}-1,
\end{aligned}
$$

where $\alpha$ is the constraint factor for plane strain/plane stress, $S_{\max } / \sigma_{0}$ is the ratio of maximum stress to its flow stress (the required stress to create plastic flow), and $R$ is the ratio of stress to each load cycle. The number of cycles required for crack growth ranges from its initial length, $a_{0}$, up to the final length, $a_{f}$. This number can be calculated by the following integral equations as follows:

$$
N_{t o t}=\int_{a_{0}}^{a_{f}} \frac{d a}{C\left(\Delta K_{e f f}\right)^{n}} .
$$

The results of the stress intensity factor in crack tip are shown in Figure 14. The results show the history of stress intensity factor for longer crack length. The longer the crack length is, the more the difference of stress intensity factor of the crack and its length uniformly increases. Based on the Paris equation, as the crack length increases, the crack growth increases. Figure 14 shows the maximum stress intensity factor of the crack with a longer length. As observed, the longer the length of the crack is, the more the difference in the stress intensity factor will be. In other words, the difference in the stress intensity factor for the crack is $2 \mathrm{~mm}$ more than its difference in the crack with an initial length of $0.5 \mathrm{~mm}$. Figure 15 shows the fatigue life obtained per the length of the crack to the different values of the initial crack length. It is shown that as the length of the crack increases, the fatigue life decreases.

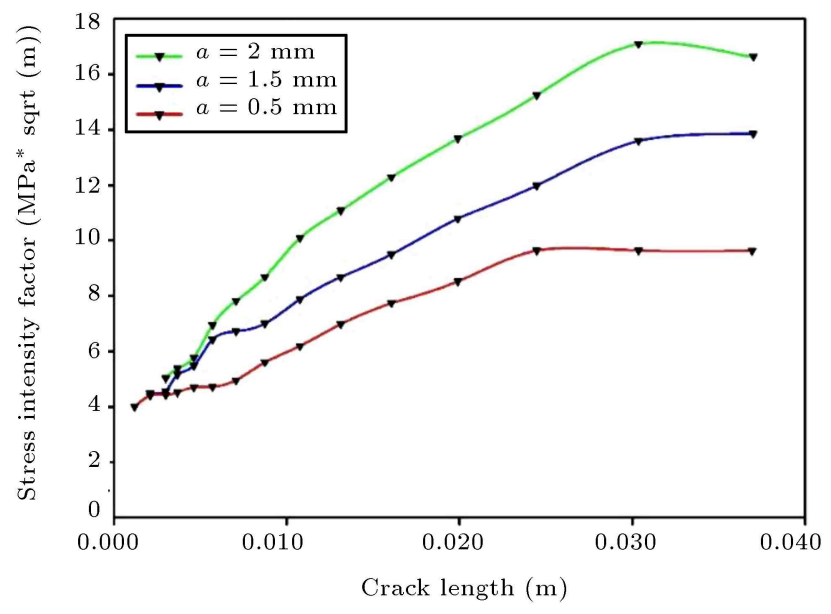

Figure 14. Stress intensity factors in the basic of different initial crack lengths in crankshaft.

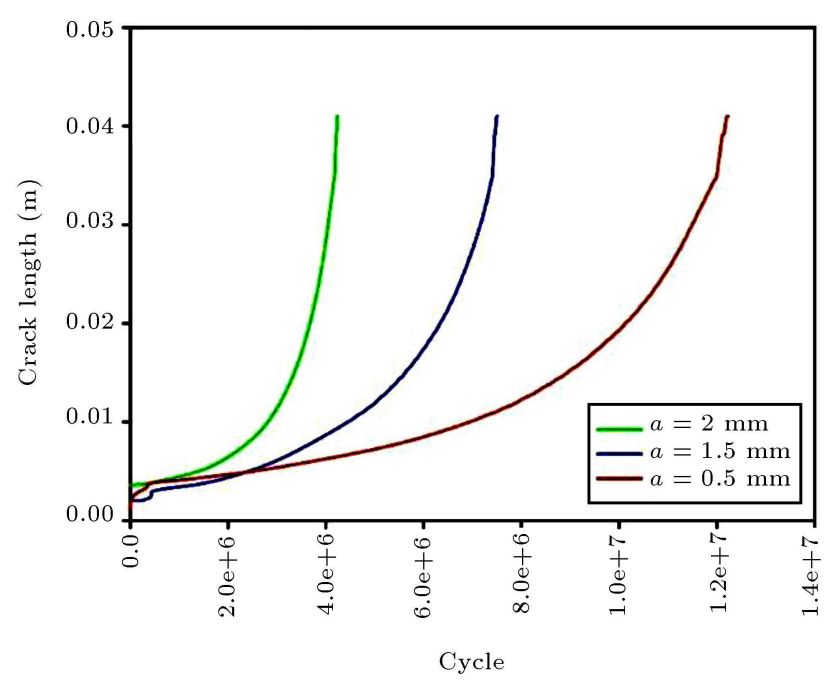

Figure 15. Fatigue life versus different initial crack lengths.

According to the results obtained from the crankshaft's fatigue life, it can be concluded that the gradient of the curve of fatigue life per crack length is negligible. In other words, a minimum increase in crack length causes maximum fatigue life, which is the reason why the stress intensity factor in short-length cracks is more important than stress intensity factor in cracks of longer length. Similar investigations of the effect of the increment of initial crack length (e.g., [27]) reported the existence and the increasing trend of fatigue life in railway wheels.

\section{Conclusions}

In this study, a 3D model was presented to demonstrate fatigue crack growth and crankshaft life estimation of the six-cylinder heavy-duty truck diesel engine. The results were obtained by a numerical method and specialized software of boundary elements. The para- 
metric analysis of the fracture was obtained using linear fracture mechanics, showing the influential factors such as crack length and loading for surface crack in the fracture. The failure occurred in the 4th crankpin of the middle part of the crankpin to the fillet of the third crankpin-web after having traveled $955000 \mathrm{~km}$. According to the cases examined by an optical microscope, it can be said that the steel microstructure is ferrite-perlite type. The micrograph of the crankshaft after getting etched and the results of hardness tests showed that the surface of the part underwent surface hardness and had a smaller microstructure than the central part. The numerical results and the fracture images show that the presence of scratches on crankpin surface is the main reason for the bending-torsional fatigue failure. This, in turn, leads to crack initiation and its propagation. The numerical results show that the maximum stress is in the fillet in the third main journal of the crankshaft. The value of the stress in the third fillet of crankpin-web is more than the center of the third crankpin from which the crack originated.

\section{References}

1. Hadipour, M., Alambeigi, F., Hosseini, R., and Masoudinejad, R. "A study on the vibrational effects of adding an auxiliary chassis to a 6-ton truck", Journal of American Science, 7(6), pp. 1219-1226 (2011).

2. Masoudi Nejad, R. "Three-dimensional analysis of rolling contact fatigue crack and life prediction in railway wheels and rails under residual stresses and wear", Ph.D. Thesis, Ferdowsi University of Mashhad, School of Mechanical Engineering (2017).

3. Masoudi Nejad, R., Farhangdoost, Kh., and Shariati, M. "Microstructural analysis and fatigue fracture behavior of rail steel", Mechanics of Advanced Materials and Structures (2018).

DOI:10.1080/15376494.2018.1472339

4. Fonte, M.A. and Freitas, M.M. "Semi-elliptical fatigue crack growth under rotating or reversed bending combined with steady torsion", Fatigue \& Fracture of Engineering Materials \& Structures, 20(6), pp. 895906 (1997).

5. Espadafor, F.J., Villanueva, J.B., and García, M.T. "Analysis of a diesel generator crankshaft failure", Engineering Failure Analysis, 16(7), pp. 2333-2341 (2009).

6. Fonte, M., Reis, L., and De Freitas, M. "Fatigue crack growth under rotating bending loading on aluminium alloy 7075-T6 and the effect of a steady torsion", Theoretical and Applied Fracture Mechanics, 80, pp. 57-64 (2015).

7. Fonte, M., Reis, L., and De Freitas, M. "The effect of steady torsion on fatigue crack growth under rotating bending loading on aluminium alloy 7075-T6", Frattura ed Integrità Strutturale, 8(30), pp. 360-368 (2014).
8. Fonte, M.D., Reis, L., Romeiro, F., Li, B., and Freitas, M. "The effect of steady torsion on fatigue crack growth in shafts", International Journal of Fatigue, 28(5-6), pp. 609-617 (2006).

9. Martins, R.F., Ferreira, L., Reis, L., and Chambel, P. "Fatigue crack growth under cyclic torsional loading", Theoretical and Applied Fracture Mechanics, 85, pp. 56-66 (2016).

10. Ghahremani Moghadam, D., Farhangdoost, Kh., and Masoudi Nejad, R. "Microstructure and residual stress distributions under the influence of welding speed in friction stir welded 2024 aluminum alloy", Metallurgical and Materials Transactions B, 47(3), pp. 2048-2062 (2016).

11. Masoudi Nejad, R. "Rolling contact fatigue analysis under influence of residual stresses", MS Thesis, Sharif University of Technology, School of Mechanical Engineering (2013).

12. Masoudi Nejad, R., Salehi, S.M., and Farrahi, G.H. "Simulation of railroad crack growth life under the influence of combination mechanical contact and thermal loads", in 3rd International Conference on Recent Advances in Railway Engineering, Iran (2013).

13. Salehi, S.M., Farrahi, G.H., Sohrabpoor, S., and Masoudi, Nejad, R. "Life estimation in the railway wheels under the influence of residual stress field", International Journal of Railway Research, 1(1), pp. 53-60 (2014).

14. Masoudi Nejad, R., Salehi, S.M., Farrahi, G.H., and Chamani, M. "Simulation of crack propagation of fatigue in Iran rail road wheels and Effect of residual stresses", in: Proceedings of the 21st International Conference on Mechanical Engineering, Iran (2013).

15. Masoudi Nejad, R., Shariati, M., and Farhangdoost, Kh. "3D finite element simulation of residual stresses in UIC60 rails during the quenching process", Thermal Science, 21(3), pp. 1301-1307 (2017).

16. Chien, W.Y., Pan, J., Close, D., and Ho, S. "Fatigue analysis of crankshaft sections under bending with consideration of residual stresses", International Journal of Fatigue, 27(1), pp. 1-19 (2005).

17. Infante, V., Silva, J.M., Silvestre, M.A.R., and Baptista, R. "Failure of a crankshaft of an aeroengine: A contribution for an accident investigation", Engineering Failure Analysis, 35, pp. 286-293 (2013).

18. De Freitas, M., Reis, L., Da Fonte, M., and Li, B. "Effect of steady torsion on fatigue crack initiation and propagation under rotating bending: Multiaxial fatigue and mixed-mode cracking", Engineering Fracture Mechanics, 78(5), pp. 826-835 (2011).

19. Moore, D.A., Packer, K.F., Jones, A.J., and Carlson, D.M. "Crankshaft failure and why it may happen again", Practical Failure Analysis, 1(3), pp. 63-72 (2001). 
20. Farrahi, G.H., Hemmati, F., Gangaraj, S.A., and Sakhaei, M. "Failure analysis of a four cylinder diesel engine crankshaft made from nodular cast iron", The Journal of Engine Research, 22, pp. 21-27 (2011).

21. Fonte, M., Anes, V., Duarte, P., Reis, L., and Freitas, M. "Crankshaft failure analysis of a boxer diesel motor", Engineering Failure Analysis, 56, pp. 109-115 (2015).

22. Masoudi Nejad, R., Farhangdoost, Kh., and Shariati, M. "Three-dimensional simulation of rolling contact fatigue crack growth in UIC60 rails", Tribology Transactions, 59(6), pp. 1059-1069 (2016).

23. Masoudi Nejad, R., Farhangdoost, Kh., Shariati, M., and Moavenian, M. "Stress intensity factors evaluation for rolling contact fatigue cracks in rails", Tribology Transactions, 60(4), pp. 645-652 (2016).

24. Shariati, M. and Masoudi Nejad, R. "Fatigue strength and fatigue fracture mechanism for spot welds in Ushape specimens", Latin American Journal of Solids and Structures, 13(15), pp. 2787-2801 (2016).

25. Shariati, M., Mohammadi, E., and Masoudi Nejad, R. "Effect of a new specimen size on fatigue crack growth behavior in thick-walled pressure vessels", International Journal of Pressure Vessels and Piping, 150, pp. 1-10 (2017).

26. Masoudi Nejad, R., Shariati M., and Farhangdoost, Kh. "Effect of wear on rolling contact fatigue crack growth in rails", Tribology International, 94, pp. 118125 (2016).

27. Masoudi Nejad, R., Farhangdoost, Kh., and Shariati, M. "Numerical study on fatigue crack growth in railway wheels under the influence of residual stresses", Engineering Failure Analysis, 52, pp. 75-89 (2015).

28. Masoudi Nejad, R. "Using three-dimensional finite element analysis for simulation of residual stresses in railway wheels", Engineering Failure Analysis, 45, pp. 449-455 (2014).

29. Masoudi Nejad, R., Shariati, M., Farhangdoost, Kh., and Atrian, A. "Rolling contact fatigue analysis of rails under the influence of residual stresses induced by manufacturing", Scientia Iranica, 26(3), pp. 14271437 (2019).

30. Fonte, M., Infante, V., Freitas, M., and Reis, L. "Failure mode analysis of two diesel engine crankshafts", Procedia Structural Integrity, 1, pp. 313-318 (2016).

31. Alfares, M.A., Falah, A.H., and Elkholy, A.H. "Failure analysis of a vehicle engine crankshaft", Journal of Failure Analysis and Prevention, 7(1), pp. 12-17 (2007).

32. Silva, F.S. "Analysis of a vehicle crankshaft failure", Engineering Failure Analysis, 10(5), pp. 605-616 (2003).

33. Becerra, J.A., Jimenez, F.J., Torres, M., Sanchez, D.T., and Carvajal, E. "Failure analysis of reciprocating compressor crankshafts", Engineering Failure Analysis, 18(2), pp. 735-746 (2011).
34. Aliakbari, K., Safarzadeh, N., and Mortazavi, S.S. "The analysis of wheel loader diesel engine crankshaft failure", International Journal of Engineering-Transactions C: Aspects, 31(3), pp. 473479 (2017).

35. Aliakbari, K. "The analysis of light-duty truck diesel engine crankshaft failure", Journal of Stress Analysis, 2(2), pp. 11-17 (2018).

36. Aliakbari, K. and Farhangdoost, K. "Plastic deformation influence on material properties of autofrettaged tubes used in diesel engines injection system", Journal of Pressure Vessel Technology, 136(4), p. 041402 (2014).

37. Aliakbari, K. and Farhangdoost, K. "The investigation of modeling material behavior in autofrettaged tubes made from aluminium alloys", International Journal of Engineering, 27, pp. 803-810 (2014).

38. Conrado, E., Gorla, C., Davoli, P., and Boniardi, M. "A comparison of bending fatigue strength of carburized and nitrided gears for industrial applications", Engineering Failure Analysis, 78, pp. 41-54 (2017).

39. ASM Handbook Committee, ASM Metals Hand Book, 12, Fractography, 2nd Edition (1992).

40. Bayrakceken, H., Ucun, I., and Tasgetiren, S. "Fracture analysis of a camshaft made from nodular cast iron", Engineering Failure Analysis, 13(8), pp. 12401245 (2006).

41. Fonte, M., Duarte, P., Reis, L., Freitas, M., and Infante, V. "Failure mode analysis of two crankshafts of a single cylinder diesel engine", Engineering Failure Analysis, 56, pp. 185-193 (2015).

42. Becerra, J.A., Jimenez, F.J., Torres, M., Sanchez, D.T., and Carvajal, E. "Failure analysis of reciprocating compressor crankshafts", Engineering Failure Analysis, 18(2), pp. 735-746 (2011).

43. Elishakoff, I., Fu, C.M., Jiang, C., Ni, B.Y., Han, X., and Chen, G.S. "Comparison of uncertainty analyses for crankshaft applications", ASCE-ASME Journal of Risk and Uncertainty in Engineering Systems, Part B: Mechanical Engineering, 1(4), p. 041002 (2015).

44. Zanotti, A., Calculation of Crankshafts for Internal Combustion Engines, Germanischer Lloyd SE, Hamburg (2012).

45. Zhang, Q., Zuo, Z., and Liu, J. "Failure analysis of a diesel engine cylinder head based on finite element method", Engineering Failure Analysis, 34, pp. 51-58 (2013).

46. Kılıçaslan, C. and İnce, U. "Failure analysis of cold forged 37Cr4 alloy M10x28 bolts", Engineering Failure Analysis, 70, pp. 177-187 (2016).

47. Montazersadgh, H.F. "Stress analysis and optimization of crankshafts subject to dynamic loading", Ph.D. Thesis, University of Toledo (2007).

48. Webster, W.D., Coffell, R., and Alfaro, D. A ThreeDimensional Finite Element Analysis of a High Speed 
Diesel Engine Connecting Rod, Society of Automotive Engineers, Warrendale, USA Technical Paper, No. 831322 (1983).

49. Cornell Fracture Group, Accessed 15 March (2015), http://www.cfg.cornell.edu.

50. FRANC3D "Concepts and user guide", Cornell Fracture Group, Cornell University, Ithaca, N.Y (1997).

51. Forman, R.G., Kearney, V.E., and Engel, R.M. "Numerical analysis of crack propagation in cyclic-loaded structures", Journal of Basic Engineering, 89, pp. 459463 (1967).

52. Elber, W. "The significance of fatigue crack closure, in damage tolerance in aircraft structures", ASTM STP, 486, pp. 230-242 (1971).

53. NASA "Fatigue Crack Growth Computer Program NASGRO Version 3.0", Reference Manual. JSC22267B, NASA, Lyndon B. Johnson Space Center, Texas (2000).

54. Anderson, T.L., Fracture Mechanics, Fundamentals and Applications, 2nd Ed. CRC press (1994).

55. Newman, J.J. "A crack opening stress equation for fatigue crack growth", International Journal of Fracture, 24(4), pp. R131-R135 (1984).

\section{Biographies}

Karim Aliakbari received his $\mathrm{PhD}$ degree from Ferdowsi University of Mashhad, Iran, 2014. He is currently an Assistant Professor at the Department of Me- chanical Engineering, Faculty of Montazeri, Khorasan Razavi Branch, Technical and Vocational University (TVU), Mashhad, Iran and, to date, he has published more than 8 journal and 2 conference papers. His research interests are in areas of finite element methods, fatigue and fracture mechanics, residual stresses, friction stir welding, and solar energy.

Mohammad Imanparast received his MSc degree from Sharif University of Technology, Iran, 2006. He is currently an Instructor at the Department of Mechanical Engineering, University of Sistan and Baluchestan, Zahedan, Iran. His research interests are in areas of finite element methods, mechanics of materials, composite materials, aeroelasticity, and structural dynamics.

Reza Masoudi Nejad received his $\mathrm{PhD}$ degree from Ferdowsi University of Mashhad, Iran, 2017. He is currently an Assistant Professor at the Department of Mechanical Engineering, Foolad Institute of Technology, Iran. To date, he has published more than 24 journal and 13 conference papers. He has recently published a book named "Mechanical design of electromechanical systems in micro-nano scale", in Sharif University of Technology Publishing. His research interests are in the areas of finite element methods, fatigue and fracture mechanics, stresses, fatigue and friction of rolling/sliding, surface science, residual stress measurement, and prediction. 